\title{
Fault geometry of 2015, Mw7.2 Murghab, Tajikistan earthquake controls rupture propagation: Insights from InSAR and seismological data
}

\author{
Simran Sangha ${ }^{\mathrm{a}}$, Gilles Peltzer ${ }^{\mathrm{a}, \mathrm{b}}$, Ailin Zhang ${ }^{\mathrm{a}}$, Lingsen Meng ${ }^{\mathrm{a}}$, Cunren \\ Liang $^{\mathrm{b}}$, Paul Lundgren ${ }^{\mathrm{b}}$, Eric Fielding ${ }^{\mathrm{b}}$ \\ ${ }^{a}$ Earth, Planetary, and Space Science Department, University of California, Los Angeles, \\ California, USA \\ ${ }^{b}$ Jet Propulsion Laboratory, California Institute of Technology, Pasadena, California, \\ USA
}

\section{Abstract}

Combining space-based geodetic and array seismology observations can provide detailed information about earthquake ruptures in remote regions. Here we use Landsat-8 imagery and ALOS-2 and Sentinel-1 radar interferometry data combined with data from the European seismology network to describe the source of the December 7, 2015, Mw7.2 Murghab (Tajikistan) earthquake. The earthquake reactivated a $\sim 79 \mathrm{~km}$-long section of the Sarez-Karakul Fault, a NE oriented sinistral, trans-tensional fault in northern Pamir. Pixel offset data delineate the geometry of the surface break and line of sight ground shifts from two descending and three ascending interferograms constrain the fault dip and slip solution. Two right-stepping, NE-striking segments connected by a more easterly oriented segment, subvertical or steeply dipping to the west were involved. The solution shows two main patches of slip with up to $3.5 \mathrm{~m}$ of left lateral slip on the southern and central fault segments. The northern segment has a left-lateral and normal oblique slip of up to a meter. Back-projection of high-frequency seismic waves 
recorded by the European network, processed using the Multitaper-MUSIC approach, focuses sharply along the surface break. The time progression of the high-frequency radiators shows that, after a 10 second initiation phase at slow speed, the rupture progresses in 2 phases at super-shear velocity $(\sim 4.3-5 \mathrm{~km} / \mathrm{s})$ separated by a 3 second interval of slower propagation corresponding to the passage through the restraining bend. The intensity of the high-frequency radiation reaches maxima during the initial and middle phases of slow propagation and is reduced by $\sim 50 \%$ during the super-shear phases of the propagation. These findings are consistent with studies of other strike-slip earthquakes in continental domain, showing the importance of fault geometric complexities in controlling the speed of fault propagation and related spatiotemporal pattern of the high-frequency radiation.

Keywords: Earthquake, Tajikistan, InSAR, Geodesy, Seismology, Back-projection

\section{1. Introduction}

2 The earthquake occurred on December 7, 2015 on the Sarez-Karakul Fault 3 (SKF), in the Gorno-Badakshan Autonomous Region of Eastern Tajikistan. 4 Its moment magnitude $(\mathrm{Mw})$ is 7.2 and its centroid moment tensor and dis5 tribution of aftershocks indicate left-lateral, strike-slip movement on a $\mathrm{NE}$ 6 oriented, nearly vertical fault (USGS, 2015). The earthquake has a similar 7 magnitude and mechanism as the Sarez-Pamir earthquake, which stroke the 8 region on 18 February 1911 (Kulikova et al., 2016). The 1911 earthquake 9 triggered a massive landslide, building a $600 \mathrm{~m}$ high dam known as the Usoi

Dam on the Murghab River, which resulted in the formation of Sarez Lake 
(Schuster and Alford, 2004; Ambraseys and Bilham, 2012). No damage to Usoi Dam was reported following the 2015 event but the seismic hazard in the region makes it a sensible target of study. Important questions to be addressed touch on the significance of the 2015 event within the current tectonic regime of the Pamir Mountains, the characterization of its rupture and direction of propagation and the possible implications for the dam stability (ISDR, 2000).

In this paper we use satellite optical and radar interferometry (InSAR) data jointly with seismological data to describe the source of the 2015 earthquake. In the following sections we summarize the tectonic setting of the region, describe the geometry of the fault rupture, and present the static slip solution obtained by inversion of InSAR data. The second part of the paper presents the seismological data used in a back-projection method to describe the rupture propagation with time. The last section discusses the correspondence between the migration of the source location of high-frequency waves with geometric complexities of the rupture and the implications of these observations.

\section{Tectonic setting}

The Pamir Mountains developed at the western syntaxis of the Himalaya collision front, north of the Indus-Tsang-Po Tertiary suture zone. They are composed of an assemblage of East-West trending belts squeezed between Paleozoic, Mesozoic, and Tertiary suture zones (Burtman and Molnar, 1993). Since the onset of the collision, north-south shortening is accommodated by 
a series of thrust systems raising the elevation of the mountains to $\sim 4500 \mathrm{~m}$, between the Tajik depression to the west and the Tarim Basin to the East (Fig. 1). Seismological (Burtman and Molnar, 1993; Pegler and Das, 1998; Sippl et al., 2013; Schurr et al., 2014) and geological observations (Tapponnier et al., 1981; Coutand et al., 2002) have shown that a large fraction of the India-Asia convergence has been absorbed by southward subduction of the Asian crust along the Main Pamir Thrust to the north and the northward subduction of the Indian plate to the south. The northward migration of the Pamir is accommodated along its eastern front by right-lateral movement on the Kashgar-Yecheng fault system and more internally by the Kongur Shan fault system, a well-developed right-lateral, transtensional fault system that connects to the Tashgorgan Fault and eventually the Karakorum Fault to the south (Robinson et al., 2004; Chevalier et al., 2011, 2015; Robinson et al., 2015; Chevalier et al., 2016). Along its western side, the northward movement of the Pamir is accommodated by left-lateral movement on a north-south shear zone including the Darvaz and the Badakhshan faults connecting to the Chaman and Herat faults to the south (Cowgill, 2010; Mohadjer et al., 2010; Schurr et al., 2014) (Fig. 1). Shallow seismicity of central and northern Pamir indicates that present-day deformation within the range is concentrated in the center and west side of the northern half of the range (Strecker et al., 1995; Sippl et al., 2013; Schurr et al., 2014; Kulikova et al., 2016). Campaign GPS velocities indicate a rather consistent NNW movement of the interior of the Pamir at a rate of $\sim 13-20 \mathrm{~mm} / \mathrm{yr}$ with respect to stable Eurasia (Reigber et al., 2001; Mohadjer et al., 2010; Zubovich et al., 2010; Ischuk et al., 2013; Zubovich et al., 2016) suggesting that the rate of the internal deformation of 
the range is low compared to the rate of convergence along the Main Pamir Thrust.

The SKF is a $\sim$ NE striking fault that extends from Sarez Lake to Karakul Lake in central northern Pamir and seems to extend towards the SW in a more distributed shear zone south of the Sarez-Murghab Thrust System (Fig. 1), (Sippl et al., 2013). A cluster of shallow seismicity occurs at the intersection of the two fault systems. A NE-SW trend of seismicity highlights the shear zone with focal solutions consistent with sinistral slip on NE oriented planes (Schurr et al., 2014). In the NE part of the Karakul Lake Valley, Strecker et al. (1995) describe the SKF surface morphology as a set of en echelon segments bearing evidence of down-dip and left-lateral movements. However, the source mechanisms of the few small earthquakes along the fault trace, the $2015 \mathrm{Mw} 7.2$ event, and its aftershocks, all indicate sinistral strike slip as opposed to oblique or normal slip (Schurr et al., 2014). Although the main fault of this asymmetric graben runs along the western side of the valley (Komatsu, 2016), south of Karakul Lake the recent faulting activity is observed along the eastern side of the valley with vertical and left-lateral offsets of glacial deposits, small stream channels, and fluvial terraces (Strecker et al., 1995; Schurr et al., 2014; Komatsu, 2016). South of the valley, the fault enters a region of high relief in the direction of Sarez Lake. Observation of the surface morphology in high resolution SPOT and Digital Globe satellite images available on the Google Earth server shows a region of rugged terrain with snow covered peaks, deeply incised valleys, steep and fast eroding slopes and many occurrences of landslides, which obscure potentially active fault scarps in the morphology. As a result, the SKF morphological 
trace cannot be followed in the area of the 2015 epicenter, which is located in the vicinity of Sarez Lake (USGS, 2015).

\section{The 2015 Murghab surface rupture and model fault geometry}

The SKF system is the only active fault system in the Pamir's interior that strikes NE and exhibits sinistral motion according to geomorphological and seismic observations (Strecker et al., 1995; Schurr et al., 2014; Kulikova et al., 2016). It is best exposed along the eastern side of the Karakul Valley between the Sarez and Karakul lakes. To determine the extent of the 2015 rupture along the fault system, we combined observations of the mainshock surface displacement obtained by pixel correlation of Landsat-8 panchromatic images and ALOS-2 radar amplitude images, along with observations of interferograms formed with Sentinel-1A and ALOS-2 radar data (Fig. 2, 3, S1, S2, S3).

The correlation of Landsat- 8 images acquired before and after the event was calculated using the COSI-Corr software (Leprince et al., 2007). Despite the severe relief of the Pamir, which resulted in a low SNR in some areas of the map, both the $\mathrm{E}$ and $\mathrm{N}$ components of surface displacement show a clear discontinuity along a $\sim 35 \mathrm{~km}$-long segment aligned with the exposed fault extending from the high relief area north of Sarez Lake to the south part of the Karakul Valley (Fig. 2 and S1). We combine the East (E) and North $(\mathrm{N})$ components of the surface displacement into the fault-parallel component $\mathrm{D}=N \times \cos (\alpha)+E \times \sin (\alpha)$, assuming a constant fault azimuth $\left(\alpha=\mathrm{N} 54.6^{\circ} \mathrm{E}\right)$ to construct the fault slip distribution curve for the section where the break 
reached the surface (Fig. 2c). The distribution shows a trimodal distribution with maxima reaching $2.7,3.7$, and $4.3 \mathrm{~m}$ along the $30 \mathrm{~km}$ section of the fault north-east of the epicenter. The fault geometry obtained with Landsat data is corroborated by the discontinuity observed in the azimuth offset field obtained with ALOS-2 radar data (Fig. S2). Despite the noise due to the lack of correlation of the amplitude pixels (see Supplementary Information), the combined observations of Landsat-8 and ALOS-2 pixel offsets allowed us to map the rupture up to the point where it enters the Karakul Valley (Fig. S2).

The fringe pattern observed in the coseismic interferograms clearly shows that the fault activated during the 2015 event extends into the Karakul Valley (Fig. 3). However, the continuity of interferometric phase across the valley indicates that the rupture did not reach the surface along that section. The density of fringes suggests that slip occurred at shallow depth under the valley floor up to the latitude of $\mathrm{N} 38^{\circ} 32^{\prime}$ (Fig. 3).

We combined these observations to construct a simplified fault model formed of two right-stepping, $\sim \mathrm{NE}$ oriented en-echelon segments, connected by a shorter segment more easterly oriented. The southern segment corresponds to the Sarez Lake area where the rupture started. The modeled fault is extended both to the north and to the south to account for possible slip at depth beyond the section that could be mapped from surface movement (Fig. 3). 


\section{InSAR data}

We used synthetic aperture radar (SAR) data from two satellite missions: the European Space Agency's (ESA) C-band Sentinel-1A and the Japan Aerospace Exploration Agency's (JAXA) L-band Advanced Land Observation Satellite 2 (ALOS-2) missions. Five interferograms spanning the mainshock event were generated using the InSAR Scientific Computing Environment (ISCE) software (Rosen et al., 2012). A modified version of ISCE was used for the ALOS-2 wide swath/stripmap data pairs (Liang and Fielding, 2016).

All interferograms were multilooked, filtered by a power-spectrum filter (Goldstein and Werner, 1998), and projected in a geographic coordinate system for further analysis. The phase unwrapping was performed using the branch-cut method (Goldstein et al., 1988) through a module of the Repeat Orbit Interferometry PACkage (ROI_PAC) software (Rosen et al., 2004), allowing us to achieve a conservative yet complete unwrapping of the coherent parts of the images in the vicinity of the surface rupture. Unlike other unwrapping approaches, this module allowed us to limit the extent of the unwrapped phase field in noisy areas and recover isolated, coherent patches of phase using manual cuts and bridges. This proved to be effective in the areas of rugged topography and in the vicinity of the surface rupture where the combined effects of foreshortening, shadow, ionospheric noise, tropospheric noise, and phase aliasing render automatic unwrapping impossible.

The ALOS-2 descending tracks and both Sentinel-1A tracks were acquired in wide swath mode and cover the full extent of the 2015 rupture while the ALOS-2 ascending tracks were acquired in stripmap mode and only partially 
cover the surface rupture (Table S1, Fig. S3). The variety of viewing directions from ascending and descending passes of the satellites offers an excellent measure of the surface displacement field around the rupture.

\section{Variable slip solution from InSAR data}

The five interferograms in Fig. S3 are used to constrain the fault geometry and kinematic parameters of the coseismic model. The data are first subsampled using a quad-tree approach to reduce the number of data points, keeping more points in the zones of higher phase gradient (Jónsson et al., 2002) (Fig. 4). The fault is approximated by three rectangular planes aligned with the surface segments determined in Section 3. The dip angles of the planar faults are not imposed and are adjusted in the inversion, while all other geometric parameters are fixed for each fault segment (Table 1). Each fault plane is divided into $2.7-3.4 \mathrm{~km} \times 2.5 \mathrm{~km}$ fault patches and the strike-slip and down-dip components of slip are estimated for each fault patch. In addition, a smoothing coefficient controlling the strength of a Laplacian smoothing operator, which is applied to two components of slip over the entire fault, is also estimated. The solution is tapered down to zero along the north, south, and bottom edges of the fault but the slip is not forced to zero along the vertical edges between contiguous fault planes.

The inversion method uses a hybrid approach combining a Bayesian approach based on the Markov chain Monte Carlo (MCMC) sampling of the parameter space defining the fault geometry and the smoothing coefficient with prior probability distributions, and a restricted, least-squares inversion 
to solve for the slip components (Fukuda and Johnson, 2008; Lundgren et al., 2013). At each sample iteration of the fault segments' dip angles and smoothing coefficient, a slip distribution solution is estimated using a singular-value decomposition (SVD) inversion with a Laplacian regularization. The solution is kept in a Markov chain if the weighted RMS of the fit is improved relative to the previous kept solution (Fukuda and Johnson, 2008). When convergence is achieved, the statistics on the solutions kept in the Markov chain give the posterior probability density distribution for the sampled parameters (Fig. 5 and S4), defining the most probable solution and confidence intervals.

The slip solution corresponding to the most probable fault geometry and smoothing coefficient is shown in Fig. 6. The three fault segments all have steep dips (Table 1) and the slip mostly horizontal (Fig. 6), consistent with the CMT solution of the event (USGS, 2015). A large patch of slip (up to $\sim 3.5 \mathrm{~m}$ ) covers about two thirds of the southern segment and most of the central segment between the surface and a depth of $\sim 15 \mathrm{~km}$. The hypocenter of the earthquake (USGS, 2015) is located at the southern end of this patch. Slip on the northern segment reaches about a meter and is rather uniformly distributed over most of the fault plane down to $20 \mathrm{~km}$. On the northern segment, the slip has a significant down-dip component consistent with normal faulting on a west dipping plane.

Our final coseismic model leads to a satisfactory fit to the five interferograms (Fig. 4). The largest misfits are observed in the near-field of the surface rupture near the junction along the central and northern segments of the fault. A reason for this misfit is the simplified geometry and slip dis- 
cretization of the modeled fault, which do not follow the likely complexities of the real breaks. The other reason of the misfit could be due to nonelastic deformation associated with ground settlement and landslides in the Karakul Valley. Ground settlement may be produced by the shaking during the earthquake or be associated with the permafrost active layer condition changes during the time spanned by interferograms. The fault runs along the eastern side of the valley where periglacial geomorphic features can be observed in Landsat-8 images and high resolution images available on Google Earth. Furthermore, two of the ALOS-2 interferograms have pre-earthquake images acquired $\sim 5$ and $\sim 16$ months before the event and they may show ground movement in the permafrost active layer in the Karakul Valley.

The CMT seismic moment for this event was reported as $\sim 7.8 \times 10^{19}$ Nm from the Global Centroid Moment Tensor catalog (GCMT) and as $\sim 10.1 \times 10^{19} \mathrm{Nm}$ from the National Earthquake Information Center (NEIC) (USGS, 2015), which respectively correspond to $57 \%$ and $74 \%$ of the total geodetic moment of $\sim 13.70 \times 10^{19} \mathrm{Nm}$ we estimated (Table 1 ). It is generally observed that the geodetic moment exceeds seismic moment. For instance, a study on sites through Mediterranean Europe and Turkey indicates that seismic moment may vary between $22-71 \%$ of the geodetic moment (Ward, 1998). All post-earthquake images used in the present study are acquired between 12 December 2015 and 13 January 2016, so the geodetic moment may include a postseismic contribution from aseismic deformation. While preseismic scenes were acquired up to 16 months before the event, the low internal rate of deformation within the interior of the Pamir (Reigber et al., 2001; Mohadjer et al., 2010; Zubovich et al., 2010, 2016) suggests there is 
unlikely a significant contribution from preseismic deformation.

\section{Seismological observations}

The kinematic rupture process of the 2015 Mw7.2 Murghab earthquake is effectively captured by the back-projection (BP) approach. We adopted the Multitaper-MUSIC array processing technique (Meng et al., 2011), which resolves closely spaced sources and is less sensitive to aliasing, yielding a sharper image of the rupture process than the standard beamforming approach (Ishii et al., 2005). We also applied a 'reference window' strategy, which eliminates the 'swimming' artifacts, a systematic apparent drift of the high-frequency energy towards the station arrays. We performed the BP analysis on coherent seismograms recorded by the European seismic network (EU), composed of 57 broadband stations evenly distributed across continental Europe with epicentral distances between $40^{\circ}$ and $60^{\circ}$ (Fig. 7b). The data of the EU network are available from the IRIS website (IRIS, 2016). The seismograms are filtered between $2 \mathrm{~s}$ and $0.5 \mathrm{~s}$, the highest band with adequate waveform coherency. The first $5 \mathrm{~s}$ of the $\mathrm{P}$-wave arrivals are aligned with a multichannel cross-correlation technique.

In standard BP, the travel times from sub-source locations to receiver stations are calculated based on 1D reference velocity models (e.g. IASP91). To account for the travel time variations due to 3D Earth structures, BP applies a timing correction inferred from the hypocenter alignment. This procedure assumes that initial $\mathrm{P}$ wave arrivals originate from the International Seismological Center (ISC) hypocenter location $\left(73.20^{\circ} \mathrm{E}, 40.38^{\circ} \mathrm{N}\right)$. A set of 
travel time errors due to 3D structures is obtained by cross-correlating the initial 5s of the $\mathrm{P}$ waves. The subsequent ruptures are tracked based on their differential travel times relative to the hypocenter. This strategy works when the source is close to the hypocenter but become less effective when the source moves away from the hypocenter. To account for the travel time error at distant source location, we apply an additional correction of slowness (ray parameter) that controls the trade-off between source location and travel time. In our previous work of the 2015 Mw7.8 Gorhka earthquake, we demonstrate that the slowness calibration effectively mitigates the spatial biases of BP source locations (Meng et al., 2016). In that paper, we also confirm that the slowness-calibrated BP resolves synthetic kinematic rupture scenarios constructed with empirical Green's functions. The correction term of slowness can be effectively calibrated using the location errors of the aftershocks. In the case of the Murghab earthquake, we derived the slowness error based on a Mw5.4 aftershock that occurred on 12/07/15 with a hypocenter of $38.64^{\circ} \mathrm{N}, 73.20^{\circ} \mathrm{E}$ at a depth of $19.9 \mathrm{~km}$, located at the northeast end of the Murghab mainshock rupture. Its catalog epicenter and the source location inferred from back-projection is shown in Fig. 7a. We compared the relative separations between the mainshock and aftershock epicenter locations-with respective uncertainties of $5.5 \mathrm{~km}$ and $5.7 \mathrm{~km}$-in both the NEIC $(\sim 60.97$ $\mathrm{km})$ and ISC ( $\sim 65.17 \mathrm{~km})$ catalogues (USGS, 2015; ISC, 2016). The relative separation of $\sim 4.2 \mathrm{~km}$ is reasonably small, which is essential for a reliable slowness calibration.

Figure 7 compares the locations of BP-inferred high-frequency radiators before and after the calibrations. Before the calibrations (Fig. 7a), the BP 
source locations are biased to the northwest of the fault surface trace. After the calibrations (Fig. 7c), the distribution of the high-frequency radiators relative to the mainshock's epicenter follows remarkably well the fault geometry derived from the satellite images. Source radiation is reliably imaged for a duration of $50 \mathrm{~s}$ indicating unilateral rupture with speed around $3 \mathrm{~km} / \mathrm{s}$ on average. Coherent energy initially emits near the hypocenter and reaches its maximum at 10s after the origin time. The high-frequency radiation continues as the rupture propagated northeastwards. At around 20s, the rupture experiences a sudden fluctuation in speed and the high-frequency energy amplifies and reaches a second maximum. This stage of rupture spatially coincides with the kink of the surface fault trace. Such geometrical barrier in non-planar faults is efficient in generating the high-frequency radiation by abruptly changing the rupture velocity and slip-rate.

At a more detailed level the time propagation of the high-frequency radiators may indicate that the rupture initiated in the vicinity of the hypocenter without a clear propagation for $\sim 10$ seconds, then propagated to the NE over a distance of $\sim 32 \mathrm{~km}$ for 6.5 seconds where it came to a halt for $\sim 3$ seconds before resuming its north-eastward propagation up to the end of the break. In this scenario, it is worth noting that the high-frequency power is released during the initiation phases of separate rupture segments and radiation power reduces when the fault propagates at faster speed (Fig. $7 \mathrm{~d}$ and e).

Such a rupture time history is similar to time profiles observed for strikeslip events of $M>7.5$ (Wang et al., 2016). In the case of the 2015 Murghab earthquake, speeds observed over the 10-16 km and 20-28 km sections of the 
fault exceed the shear waves velocities of $3.55-3.6 \mathrm{~km} / \mathrm{s}$ that are reported for the upper crust in this part of Pamir(Mechie et al., 2012).

\section{Discussion}

The December 2015 Murghab event reactivated a $~ 79$ km-long section of the SKF in northern Pamir. The 3-segment fault model obtained from Landsat-8 pixels offsets and inversion of InSAR data have steep dip angles toward the west in agreement with the narrow zone of seismicity observed across Karakul Lake down to a depth of $20 \mathrm{~km}$ (Schurr et al., 2014). The slip solution indicates sinistral slip of up to $3.5 \mathrm{~m}$ and a small normal component of up to $1 \mathrm{~m}$ along the northern segment, south of Karakul Lake. This solution is consistent with the regional seismicity of northern Pamir interior, which shows predominantly strike-slip mechanisms on NE-oriented planes (Schurr et al., 2014) and the fault trace morphology typical of trans-tensional fault systems in the Karakul Valley (Strecker et al., 1995).

The Murghab earthquake fault is formed of two right-stepping segments connected by a more easterly oriented segment in the restraining bend. This geometry seems to have controlled the rupture propagation velocity and the generation of high-frequency energy. From the epicenter near the southern end of the fault the rupture propagated at a slow rate for about $10 \mathrm{~s}$ before speeding up to super shear velocity $(\sim 5 \mathrm{~km} / \mathrm{s})$ for $6.5 \mathrm{~s}$ until it reached the restraining bend between the two main segments. Between 16.5 and 19.5 seconds the rupture pursued its propagation at a slower rate and sped up again at a rate of $\sim 4.4 \mathrm{~km} / \mathrm{s}$ for $8.5 \mathrm{~s}$ to break the third segment of the fault. 
Super-shear rupture propagation seems to be common for large strike-slip events in the continental domain (e.g., Bouchon and Vallée, 2003; Avouac et al., 2014; Wang et al., 2016). For example, in the case of the 2001 Kunlun event, a 3-phase rupture propagation scenario was proposed in which the middle (Kusai) segment appears to have ruptured at a speed of $6 \mathrm{~km} / \mathrm{s}$ over a distance of $175 \mathrm{~km}$ (Vallée et al., 2008). The abrupt end of the super-shear segment corresponds to a fault geometric complexity where the main Kunlun fault splits into the Xidatai segment to the North and the Kunlun Pass segment to the South (Lasserre et al., 2005; Klinger et al., 2006). In addition, the decrease of the rupture speed appears to correspond to an increase in radiation of high-frequency amplitude (Vallée et al., 2008). Such characteristics corresponds to our observations of the 2015 Murghab event rupture propagation where a restraining bend in the central part of the rupture appears to have slowed down its propagation for about 3 seconds between two linear sections rupturing at super-shear velocities. Moreover, the high-frequency radiation history we observe shows two maxima corresponding to the slow phases of the rupture, first near the hypocenter at break initiation and second through the restraining bend of the fault.

Super-shear ruptures generate strong shaking of the ground, preferentially in the direction they propagate. The NE propagation of the 2015 rupture may have focused most of its shaking energy away from Sarez Lake, thus preserving the dam formed by the landslide that was triggered by the SarezPamir earthquake in 1911. A close look at the pixel offset map around the western termination of Sarez Lake reveals that the lake banks along its northern and southern shores settled down into the lake by several meters 
(Fig. 8). While most of the land that was mobilized during the 1911 landslide appears stable in the coseismic displacement map, a section of its eastern edge moved $\sim 3 \mathrm{~m}$ toward the lake and its southern edge moved up to $5 \mathrm{~m}$ toward the south into Shadau Lake. A more severe landslide, mobilizing an area of $\sim 1.6 \mathrm{~km}^{2}$ with $17 \mathrm{~m}$ of horizontal shift toward the NE is visible along the SW shore of the Sarez Lake (Fig. 8). The landslide corresponds to the collapse of a steep slope reactivating a large open fracture at the crest line.

The significance of the Sarez-Karakul fault in north central Pamir is difficult to determine because of its slow rate compared to the rates of faults occurring along the edges of the range (Schurr et al., 2014). Possible extension of the fault southwest of the Sarez Lake is unclear in the morphology because of the high and rapidly eroding relief of the Western Pamir. However, a NE-SW alignment of seismicity extends south of the Sarez-Murghab Thrust system with focal mechanisms consistent with sinistral slip on NE-oriented planes (Schurr et al., 2014). The shear zone highlighted by this alignment of seismicity and the SKF together may define an incipient, NE-trending transtensional, sinistral system that isolates the NW corner of the Pamir, allowing its westward extrusion towards the Tajik Basin. The movement of the crustal corner is accommodated to the north along the Main Pamir Thrust (MPT), as evidenced in GPS measurements across the Ali Valley (Zubovich et al., 2016), and is gradually absorbed in the fold belt developed in the sedimentary cover of the Tajik basin and the subduction of the Afghan lithospheric mantle under the western Pamir (Schurr et al., 2014).

The localized extension developing in northern Pamir along the sinistral, NE-trending and dextral, NW-trending conjugate systems can be com- 
pared with the fault systems developing in southern Tibet where north-south graben valleys develop at the termination of stepping strike-slip faults (e.g., Armijo et al., 1989). Copley et al. (2011) argue that the coupling between the subducting Indian mantle and the crust in southern Tibet is required to allow normal faulting to develop in a north-south convergence setting. The same argument may apply to northern Pamir, which is overlaying the Asian mantle lithosphere along the north Pamir thrust (e.g., Pegler and Das, 1998; Mechie et al., 2012). The normal component of movement observed along the SKF and other graben systems in northern Pamir may indicate a high level of coupling between the Pamir lower crust and the Asian mantle.

\section{Conclusion}

We have shown that the Mw7.2, 2015 Murghab earthquake ruptured three segments of the Sarez-Karakul Fault that are steeply dipping to the northwest and organized in a right-stepping configuration. The fault slip-solution obtained by inversion of InSAR data shows two main patches of up to 3.5 $\mathrm{m}$ of left slip on the south and central segments and oblique, normal and left slip of up to $1 \mathrm{~m}$ on the northern segment. Back-projection of the $0.5-2$ seconds band period of the seismic waves onto the fault plane reveals the complexity of the rupture propagation through time. After an initiation phase characterized by high energy radiation and slow propagation velocity, the rupture accelerated to $\sim 5 \mathrm{~km} / \mathrm{s}$ over a distance of $30 \mathrm{~km}$, slowed down for about 3 seconds along the restraining bend segment of the fault and sped up again at super-shear velocity along its last segment. The coincidence of 
the high-frequency radiators' location and rupture history observed in the seismological record, and the fault geometry and static solution derived from space-based geodesy is remarkable. These findings show the capability of the back-projection method, enhanced by aftershock calibrations, to describe details of the rupture kinematics of a moderate size event in a remote part of the world.

\section{Acknowledgments}

We thank M.-H. Huang and C. Yin for discussions on inversion approaches. Two anonymous reviewers gave detailed and constructive comments that improved the original manuscript. European Space Agency, Copernicus Sentinel data 2015, retrieved from ASF DAAC 7 January 2016. ALOS-2 data were provided by the Japan Aerospace Exploration Agency (JAXA) under PI Project P1372. Panchromatic Remote-sensing instrument for Stereo Mapping (PRISM) data was obtained from JAXA (http://www.eorc.jaxa.jp/ALOS/en/aw3d30/). The Incorporated Research Institutions for Seismology (IRIS) (www.iris.edu) and the European ORFEUS (www.orfeus-eu.org) data centers provided access to broadband seismograms. The earthquake catalogs were obtained from the International Seismological Center (ISC) bulletin (http://www.isc.ac.uk/), National Earthquake Information Center (NEIC) (http://earthquake.usgs.gov/), and IRIS (http://ds.iris.edu/). A. Zhang was supported by NSF EarthScope proposal EAR-1614609. Some figures were prepared using the Generic Mapping Tools (GMT; Wessel and Smith (1998)). The work was done in part at the Jet 
${ }_{427}$ Propulsion Laboratory, California Institute of Technology under contract 428 with NASA.

429 
Ambraseys, N., Bilham, R., 2012. The Sarez-Pamir Earthquake and Landslide of 18 February 1911. Seismol. Res. Lett. 83, 294-314. http: //dx.doi.org/10.1785/gssrl.83.2.294.

Armijo, R., Tapponnier, P., Han, T., 1989. Late Cenozoic right-lateral strikeslip faulting in southern Tibet. Journal of Geophysical Research: Solid Earth 94, 2787-2838. http://dx.doi.org/10.1029/JB094iB03p02787.

Avouac, J.P., Ayoub, F., Wei, S., Ampuero, J.P., Meng, L., Leprince, S., Jolivet, R., Duputel, Z., Helmberger, D., 2014. The 2013, Mw 7.7 Balochistan earthquake, energetic strike-slip reactivation of a thrust fault. Earth and Planetary Science Letters 391, 128-134. http://dx.doi.org/10.1016/ j.epsl.2014.01.036.

Bouchon, M., Vallée, M., 2003. Observation of long supershear rupture during the magnitude 8.1 Kunlunshan earthquake. Science 301, 824-826. http: //dx.doi.org/10.1126/science.1086832.

Burtman, V.S., Molnar, P., 1993. Geological and geophysical evidence for deep subduction of continental crust beneath the Pamir. Special Paper 281, 1-76. http://dx.doi.org/10.1130/SPE281-p1.

Chevalier, M.L., Leloup, P.H., Li, H., 2016. Comment on No late Quaternary strike-slip motion along the northern Karakoram fault published by robinson et al. in epsl, 2015. Earth and Planetary Science Letters 443, 216-219. http://dx.doi.org/10.1016/j.epsl.2016.03.031.

Chevalier, M.L., Li, H., Pan, J., Pei, J., Wu, F., Xu, W., Sun, Z., Liu, D., 2011. Fast slip-rate along the northern end of the Karakorum fault system, 
western Tibet. Geophysical Research Letters 38. http://dx.doi .org/10. 1029/2011GL049921.

Chevalier, M.L., Pan, J., Li, H., Liu, D., Wang, M., 2015. Quantification of both normal and right-lateral late Quaternary activity along the Kongur Shan extensional system, Chinese Pamir. Terra Nova 27, 379-391. http: //dx.doi.org/10.1111/ter.12170.

Copley, A., Avouac, J.P., Wernicke, B.P., 2011. Evidence for mechanical coupling and strong Indian lower crust beneath southern Tibet. Nature 472, 79-81. http://dx.doi.org/10.1038/nature09926.

Coutand, I., Strecker, M.R., Arrowsmith, J.R., Hilley, G., Thiede, R.C., Korjenkov, A., Omuraliev, M., 2002. Late Cenozoic tectonic development of the intramontane Alai Valley, (Pamir-Tien Shan region, central Asia): An example of intracontinental deformation due to the Indo-Eurasia collision. Tectonics. 21, 1053-1071. http://dx.doi.org/10.1029/2002TC001358.

Cowgill, E., 2010. Cenozoic right-slip faulting along the eastern margin of the Pamir salient, northwestern China. Geological Society of America Bulletin 122, 145-161. http://dx.doi.org/10.1130/B26520.1.

Fukuda, J., Johnson, K.M., 2008. A fully Bayesian inversion for spatial distribution of fault slip with objective smoothing. Bulletin of the Seismological Society of America 98, 1128-1146. http://dx.doi.org/10.1785/ 0120070194.

Goldstein, R.M., Werner, C.L., 1998. Radar interferogram filtering for 
geophysical applications. Geophysical Research Letters 25, 4035-4038. http://dx.doi.org/10.1029/1998GL900033.

Goldstein, R.M., Zebker, H.A., Werner, C.L., 1988. Satellite radar interferometry: Two-dimensional phase unwrapping. Radio science 23, 713-720. http://dx.doi.org/10.1029/RS023i004p00713.

IRIS, 2016. Moment Tensor for MW 7.2 (GCMT) TAJIKISTAN (Inactive). http://ds.iris.edu/spud/momenttensor/11031297. [Online; accessed September-2016]. http://dx.doi.org/doi:10.17611/DP/11031297.

ISC, 2016. ISC Bulletin: event catalogue search. http://www.isc.ac.uk/ iscbulletin/search/catalogue/. [Online; accessed September-2016].

Ischuk, A., Bendick, R., Rybin, A., Molnar, P., Khan, S.F., Kuzikov, S., Mohadjer, S., Saydullaev, U., Ilyasova, Z., Schelochkov, G., Zubovich, A.V., 2013. Kinematics of the Pamir and Hindu Kush regions from GPS geodesy. Journal of geophysical research: solid earth 118, 2408-2416. http: //dx.doi.org/10.1002/jgrb.50185.

ISDR, 2000. Usoi Landslide Dam and Lake Sarez - An Assessment of Hazard and Risk in the Pamir Mountains, Tajikistan. 1, United Nations Publication.

Ishii, M., Shearer, P.M., Houston, H., Vidale, J.E., 2005. Extent, duration and speed of the 2004 Sumatra-Andaman earthquake imaged by the Hi-Net array. Nature 435, 933-936. http://dx.doi.org/10.1038/ nature03675. 
Jónsson, S., Zebker, H., Segall, P., Amelung, F., 2002. Fault slip distribution of the $1999 \mathrm{Mw} 7.1$ Hector Mine, California, earthquake, estimated from satellite radar and GPS measurements. Bulletin of the Seismological Society of America 92, 1377-1389. http://dx.doi.org/10.1785/ 0120000922.

Klinger, Y., Michel, R., King, G., 2006. Evidence for an earthquake barrier model from $\mathrm{Mw} \sim 7.8$ Kokoxili (Tibet) earthquake slip-distribution. Earth and Planetary Science Letters 242, 354-364. http://dx.doi.org/10. 1016/j.epsl.2005.12.003.

Komatsu, T., 2016. Geomorphic Features of the Eastern Pamirs, with a Focus on the Occurrence of Intermontane Basins, in: Mapping Transition in the Pamirs. Springer, pp. 55-68. http://dx.doi.org/10.1007/ 978-3-319-23198-3_4.

Kulikova, G., Schurr, B., Krüger, F., Brzoska, E., Heimann, S., 2016. Source parameters of the Sarez-Pamir earthquake of 1911 February 18. Geophys. J. Int. 205, 1086-1098. http://dx.doi.org/10.1093/gji/ggw069.

Lasserre, C., Peltzer, G., Crampé, F., Klinger, Y., Van Der Woerd, J., Tapponnier, P., 2005. Coseismic deformation of the $2001 \mathrm{Mw}=7.8$ Kokoxili earthquake in Tibet, measured by synthetic aperture radar interferometry. Journal of Geophysical Research: Solid Earth 110. http: //dx.doi.org/10.1029/2004JB003500.

Leprince, S., Barbot, S., Ayoub, F., Avouac, J.P., 2007. Automatic and precise orthorectification, coregistration, and subpixel correlation of satellite 
images, application to ground deformation measurements. Geoscience and Remote Sensing, IEEE Transactions on 45, 1529-1558. http://dx.doi. org/10.1109/TGRS . 2006.888937.

Liang, C., Fielding, E.J., 2016. Interferometric Processing of ScanSAR Data Using Stripmap Processor: New Insights From Coregistration. IEEE Transactions on Geoscience and Remote Sensing 54, 4343-4354. http: //dx.doi.org/10.1109/TGRS. 2016.2539962.

Lundgren, P., Poland, M., Miklius, A., Orr, T., Yun, S.H., Fielding, E., Liu, Z., Tanaka, A., Szeliga, W., Hensley, S., et al., 2013. Evolution of dike opening during the March 2011 Kamoamoa fissure eruption, K̄̄lauea Volcano, Hawaii. Journal of Geophysical Research: Solid Earth 118, 897914. http://dx.doi.org/10.1002/jgrb.50108.

Mechie, J., Yuan, X., Schurr, B., Schneider, F., Sippl, C., Ratschbacher, L., Minaev, V., Gadoev, M., Oimahmadov, I., Abdybachaev, U., et al., 2012. Crustal and uppermost mantle velocity structure along a profile across the Pamir and southern Tien Shan as derived from project TIPAGE wide-angle seismic data. Geophysical Journal International 188, 385-407. http://dx.doi.org/10.1111/j.1365-246X.2011.05278.x.

Meng, L., Inbal, A., Ampuero, J.P., 2011. A window into the complexity of the dynamic rupture of the 2011 Mw 9 Tohoku-Oki earthquake. Geophysical Research Letters 38. http://dx.doi.org/10.1029/2011GL048118.

Meng, L., Zhang, A., Yagi, Y., 2016. Improving back projection imaging with a novel physics-based aftershock calibration approach: A case study 
of the 2015 Gorkha earthquake. Geophysical Research Letters 43, 628-636. http://dx.doi.org/10.1002/2015GL067034.

Mohadjer, S., Bendick, R., Ischuk, A., Kuzikov, S., Kostuk, A., Saydullaev, U., Lodi, S., Kakar, D., Wasy, A., Khan, M., et al., 2010. Partitioning of India-Eurasia convergence in the Pamir-Hindu Kush from GPS measurements. Geophys. Res. Lett. 37. http://dx.doi.org/10.1029/ 2009 GL041737.

Pegler, G., Das, S., 1998. An enhanced image of the Pamir-Hindu Kush seismic zone from relocated earthquake hypocentres. Geophys. J. Int. 134, 573-595. http://dx.doi.org/10.1046/j.1365-246x.1998.00582.x.

Reigber, C., Michel, G., Galas, R., Angermann, D., Klotz, J., Chen, J., Papschev, A., Arslanov, R., Tzurkov, V., Ishanov, M., 2001. New space geodetic constraints on the distribution of deformation in Central Asia. Earth and Planetary Science Letters 191, 157-165. http://dx.doi.org/ 10.1016/S0012-821X(01)00414-9.

Robinson, A., Yin, A., Manning, C., Harrison, T., Zhang, S.H., Wang, X., 2004. Tectonic evolution of the northeastern Pamir: Constraints from the northern portion of the Cenozoic Kongur Shan extensional system, western China. Geol. Soc. Am. Bull. 116, 953-973. http://dx.doi.org/10.1130/ B25375.1.

Robinson, A.C., Owen, L.A., Chen, J., Schoenbohm, L.M., Hedrick, K.A., Blisniuk, K., Sharp, W.D., Imrecke, D.B., Li, W., Yuan, Z., et al., 2015. No late Quaternary strike-slip motion along the northern Karakoram fault. 
Earth and Planetary Science Letters 409, 290-298. http://dx.doi.org/ 10.1016/j.epsl.2014.11.011.

Rosen, P.A., Gurrola, E., Sacco, G.F., Zebker, H., 2012. The InSAR scientific computing environment, in: Synthetic Aperture Radar, 2012. EUSAR. 9th European Conference on, VDE. pp. 730-733.

Rosen, P.A., Hensley, S., Peltzer, G., Simons, M., 2004. Updated repeat orbit interferometry package released. Eos, Transactions American Geophysical Union 85, 47-47. http://dx.doi.org/10.1029/2004E0050004.

Schurr, B., Ratschbacher, L., Sippl, C., Gloaguen, R., Yuan, X., Mechie, J., 2014. Seismotectonics of the Pamir. Tectonics. 33, 1501-1518. http: //dx.doi.org/10.1002/2014TC003576.

Schuster, R.L., Alford, D., 2004. Usoi Landslide Dam and Lake Sarez, Pamir Mountains, Tajikistan. Environmental \& Engineering Geoscience 10, 151168. http://dx.doi.org/10.2113/10.2.151.

Sippl, C., Schurr, B., Yuan, X., Mechie, J., Schneider, F.M., Gadoev, M., Orunbaev, S., Oimahmadov, I., Haberland, C., Abdybachaev, U., Minaev, V., Negmatullaev, S., Radjabov, N., 2013. Geometry of the Pamir-Hindu Kush intermediate-depth earthquake zone from local seismic data. J. Geophys. Res. 118, 1438-1457. http://dx.doi.org/10.1002/jgrb.50128.

Strecker, M.R., Frish, W., Hamburger, M.W., Ratschbacher, L., Semiletkin, S., Zamoryyev, A., Sturchio, N., 1995. Quaternary deformation in the Eastern Pamirs, Tadzhikistan and Kyrgyzstan. Tectonophysics. 14, 10611079. http://dx.doi.org/10.1029/95TC00927. 
Tapponnier, P., Mattauer, M., Proust, F., Cassaigneau, C., 1981. Mesozoic Ophiolites, Sutures, and Large-Scale Tectonic Movements in Afghanistan. Earth Planet. Sci. Lett. 52, 355-371. http://dx.doi.org/10.1016/ 0012-821X (81) 90189-8.

USGS, 2015. M7.2 - 104km W of Murghob, Tajikistan. http://earthquake. usgs.gov/earthquakes/eventpage/us100044k6\#general. [Online; accessed December-2015].

Vallée, M., Landès, M., Shapiro, N.M., Klinger, Y., 2008. The 14 November 2001 Kokoxili (Tibet) earthquake: High-frequency seismic radiation originating from the transitions between sub-Rayleigh and supershear rupture velocity regimes. Journal of Geophysical Research: Solid Earth 113. http://dx.doi.org/10.1029/2007JB005520.

Wang, D., Mori, J., Koketsu, K., 2016. Fast rupture propagation for large strike-slip earthquakes. Earth and Planetary Science Letters 440, 115-126. http://dx.doi.org/10.1016/j.epsl.2016.02.022.

Ward, S.N., 1998. On the consistency of earthquake moment release and space geodetic strain rates: Europe. Geophysical Journal International 135, 1011-1018. http://dx.doi.org/10.1046/j.1365-246X. 1998.t01-2-00658.x.

Wessel, P., Smith, W.H., 1998. New, improved version of Generic Mapping Tools released. Eos, Transactions American Geophysical Union 79, 579579. http://dx.doi.org/10.1029/98E000426. 
611

612

613

614

615

616

617

618

Zubovich, A.V., Schne, T., Metzger, S., Mosienko, O., Mukhamediev, S., Sharshebaev, A., Zech, C., 2016. Tectonic interaction between the Pamir and Tien Shan observed by GPS. Tectonics. 35. http://dx.doi .org/10. 1002/2015TC004055.

Zubovich, A.V., Wang, X., Sherba, Y.G., Schelochkov, G.G., Reilinger, R., Reigber, C., Mosienko, O.I., Molnar, P., et al., 2010. GPS velocity field for the Tien Shan and surrounding regions. Tectonics. 29. http://dx.doi. org/10.1029/2010TC002772. 


\begin{tabular}{|c|c|c|c|c|c|c|c|}
\hline $\begin{array}{c}\text { Fault } \\
\text { seg. }\end{array}$ & $\begin{array}{c}\text { Center Lat. } \\
\left({ }^{\circ} \mathrm{N}\right)\end{array}$ & $\begin{array}{c}\text { Center Lon. } \\
\left({ }^{\circ} \mathrm{E}\right)\end{array}$ & $\begin{array}{c}\text { Strike } \\
\left({ }^{\circ}\right)\end{array}$ & $\begin{array}{c}\text { Width } \\
(\mathrm{km})\end{array}$ & $\begin{array}{c}\text { Length } \\
(\mathrm{km})\end{array}$ & $\begin{array}{c}\text { Dip } \\
\text { solution }\left(^{\circ}\right)\end{array}$ & $\begin{array}{c}\text { Geo. moment } \\
\left(10^{19} \mathrm{Nm}\right)\end{array}$ \\
\hline 1 & 38.261 & 72.834 & 215.4 & 30 & 41.22 & $91 E+2.3 /-6.8$ & 8.271 \\
\hline 2 & 38.442 & 73.023 & 234.6 & 30 & 12.56 & $80 W+9.3 /-7.2$ & 2.059 \\
\hline 3 & 38.578 & 73.159 & 210.1 & 30 & 26.55 & $83 W+8.2 /-3.5$ & 3.396 \\
\hline
\end{tabular}

Table 1: All geometric parameters other than dip are fixed for each fault segment. Top of each fault segment is fixed at surface. Geodetic moments are calculated assuming upper crustal shear modulus of $30 \mathrm{GPa}$. Total geodetic moment for modeled fault is $\sim 13.70 \times 10^{19}$ Nm. 


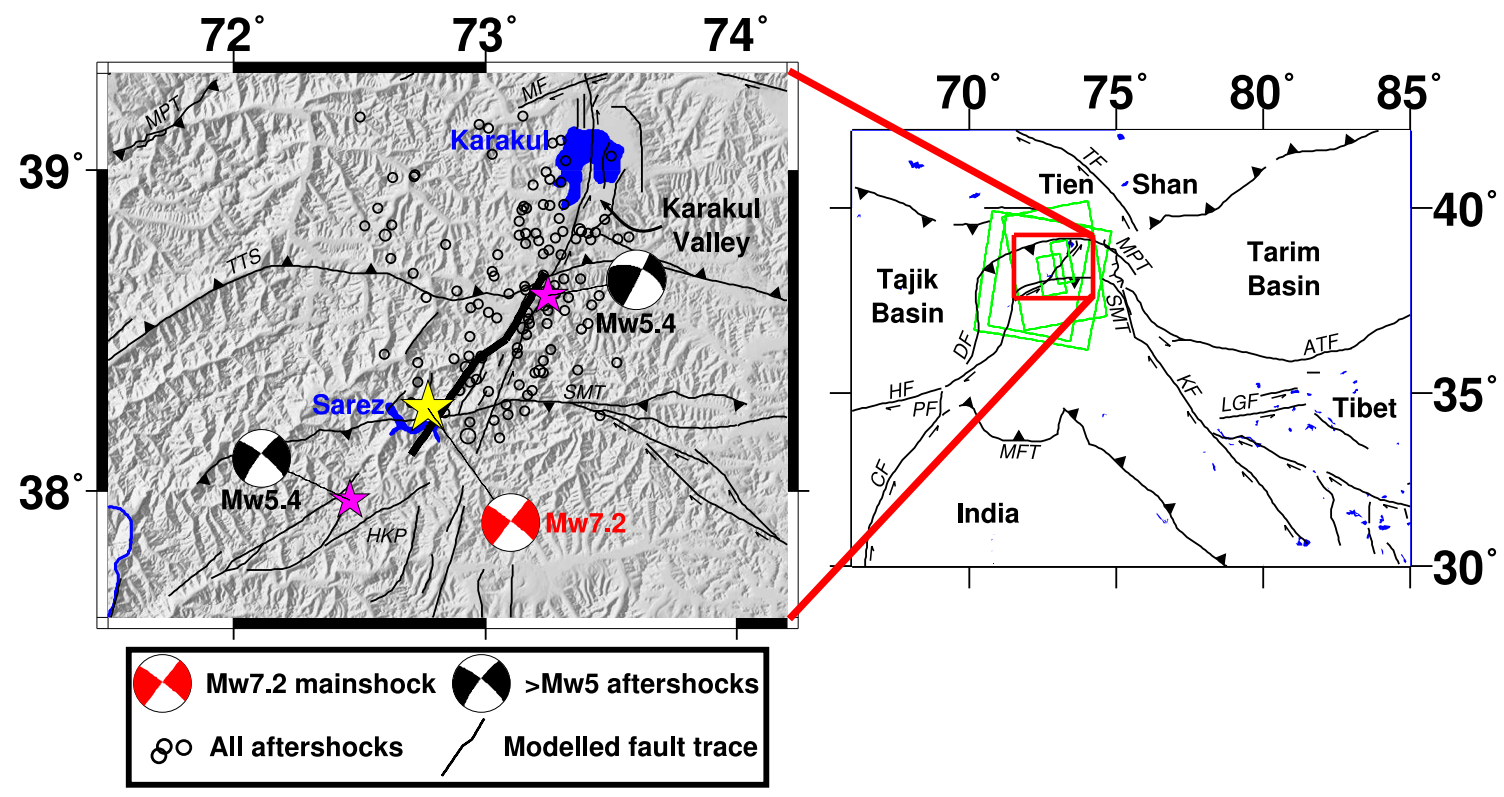

Figure 1: Simplified tectonics map of Central Pamir. 2015 Sarez Lake Mw7.2 mainshock (yellow star), two Mw5.4 aftershocks (magenta stars) plotted with accompanying focal mechanisms from the Incorporated Research Institutions for Seismology (IRIS) (IRIS, 2016), and background seismicity (open dots) data from the International Seismological Centre (ISC) (ISC, 2016). Quaternary faults from (Mohadjer et al., 2016) shown in black. Coseismic fault trace in thick black (this study). Inset map provides location of study area (red box), with major faults (black). Fault abbreviations are Altyn Tagh Fault= $\mathrm{ATF}, \mathrm{CF}=$ Chaman fault, $\mathrm{DF}=$ Darvaz-Karakul fault, $\mathrm{HF}=$ Herat fault, $\mathrm{HKP}=$ Hindu Kush-Pamir faults, $\mathrm{KF}=$ Karakorum fault, $\mathrm{LGF}=$ Longmu-Gozha fault, $\mathrm{MFT}=$ Main frontal thrust, $\mathrm{MPT}=$ Main Pamir thrust, $\mathrm{MF}=$ Muji Fault, $\mathrm{PF}=$ Paghman fault, $\mathrm{SKF}=$ Sarez-Karakul fault system, SMT $=$ Sarez-Murghab thrust system, TF $=$ Talas Ferghana fault, and TTS =Tanymas thrust system. Green frames are locations of five InSAR images from Sentinel-1A and ALOS-2 satellites used in this study. 

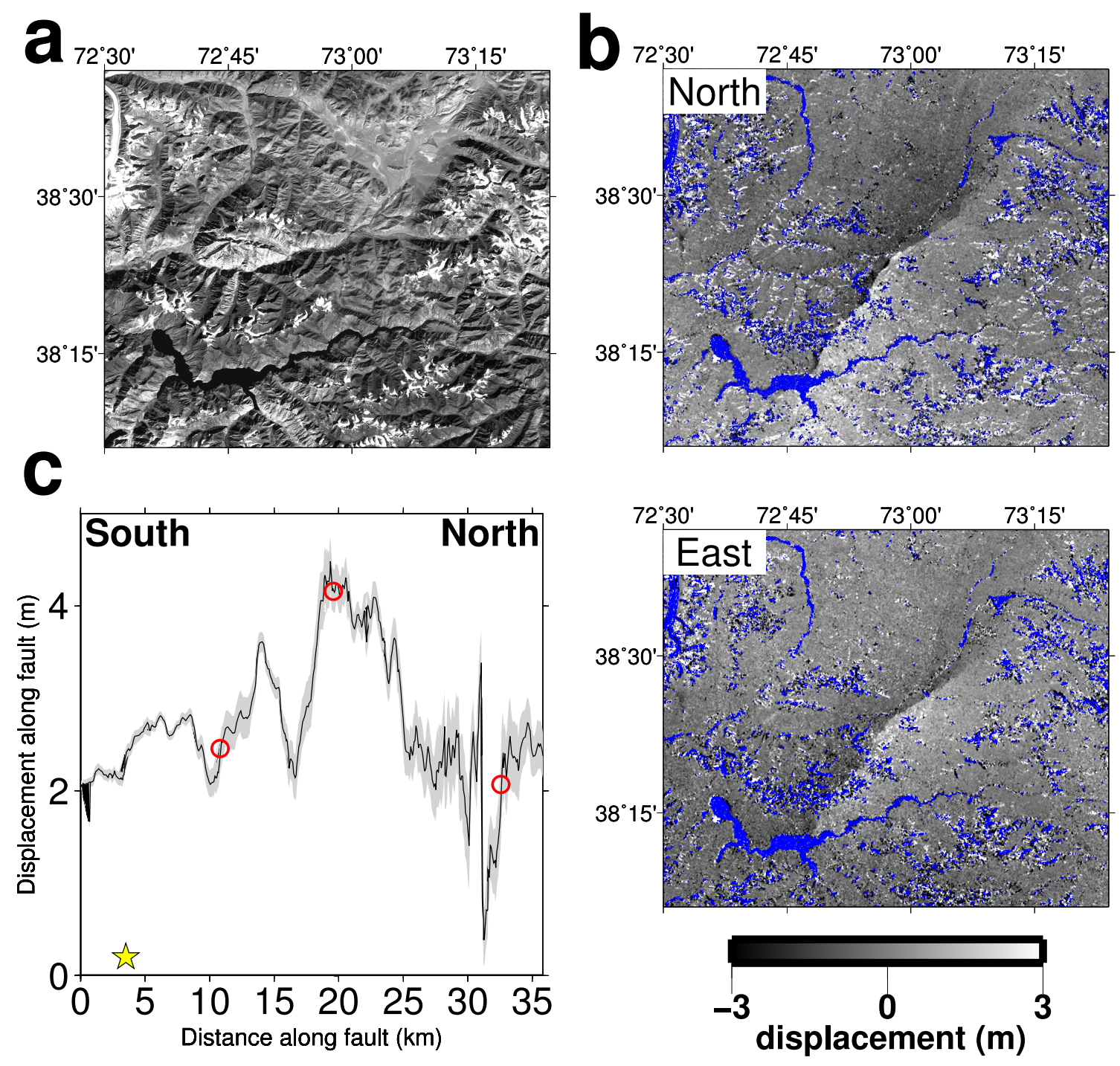

Figure 2: (a) Post-earthquake Landsat-8 panchromatic band image (15 m spatial resolution). (b) North and East components of surface displacement generated from pre-and post-earthquake Landsat-8 images acquired on 10/13/2015 and 10/15/2016, respectively. Low signal-to-noise areas are masked for clarity, and no-data values are colored blue. (c) Left-lateral slip distribution along fault, taken from horizontal ground displacement projected on fault average direction $\left(\mathrm{N} 54.6^{\circ} \mathrm{E}\right)$. Gray shade indicates $+/-1 \sigma$ uncertainty. Star is projected epicenter location. Red circles correspond to along-strike location of fault-perpendicular profiles shown in Fig. S1. 
Sentinel-1A 20151206-20151230

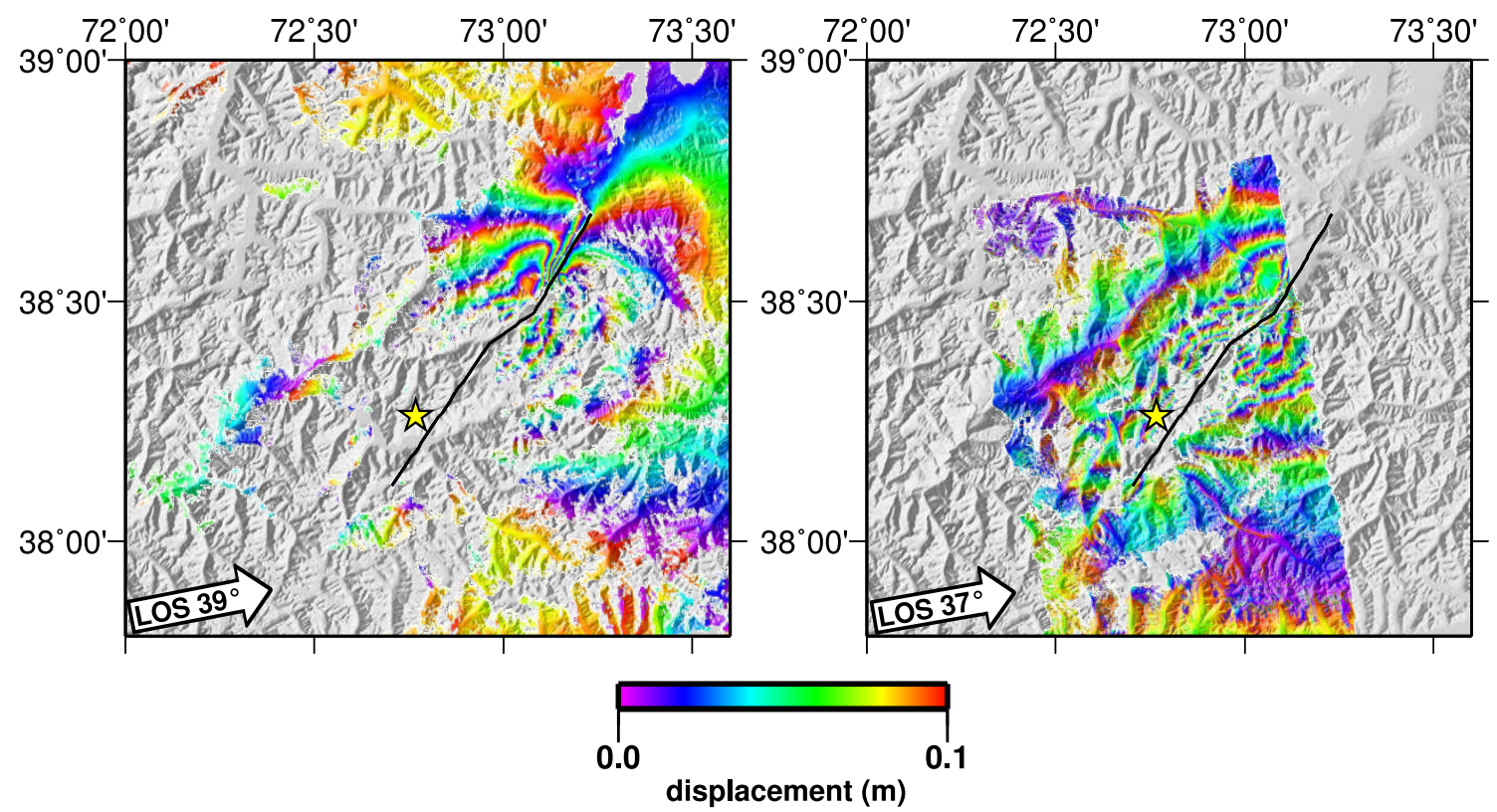

Figure 3: Example of two interferograms used in this study, all unwrapped interferograms are plotted in Fig. S3). Unwrapped phase is re-wrapped so that each color cycle (redgreen-blue-red) represents $10 \mathrm{~cm}$ of displacement towards the satellite. Arrows indicate direction of LOS with indication of mean incidence angle. Modeled coseismic fault trace is shown in black. Gray areas are zones of low signal coherence where the phase could not be unwrapped. 


\section{Observed Interferograms}
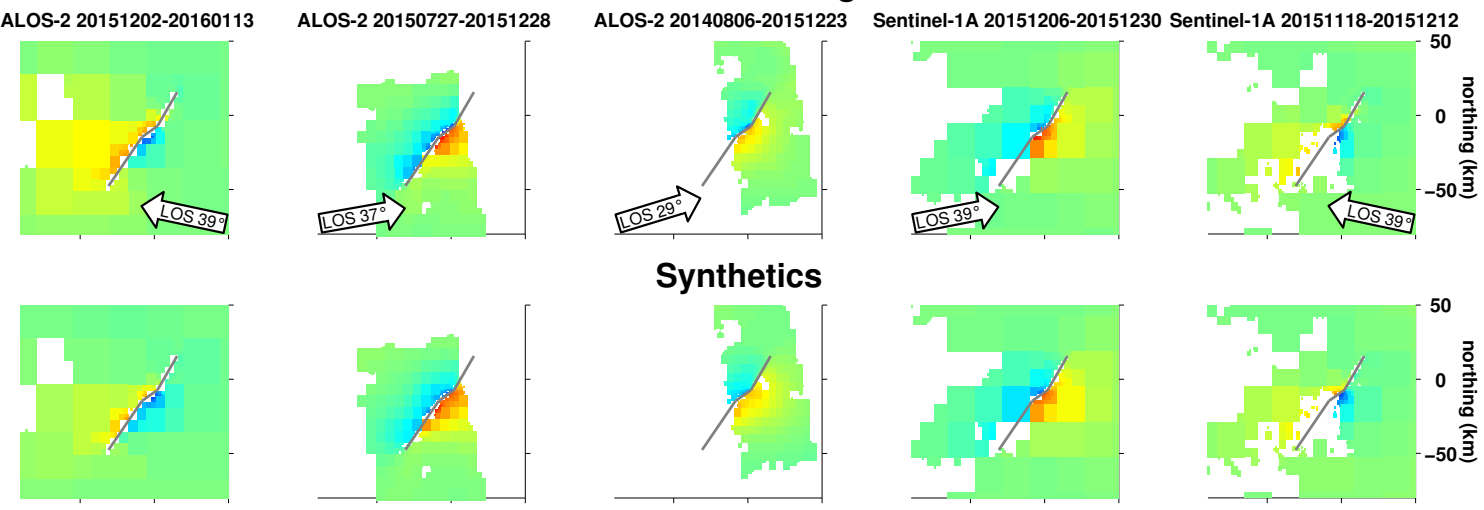

\section{Synthetics}
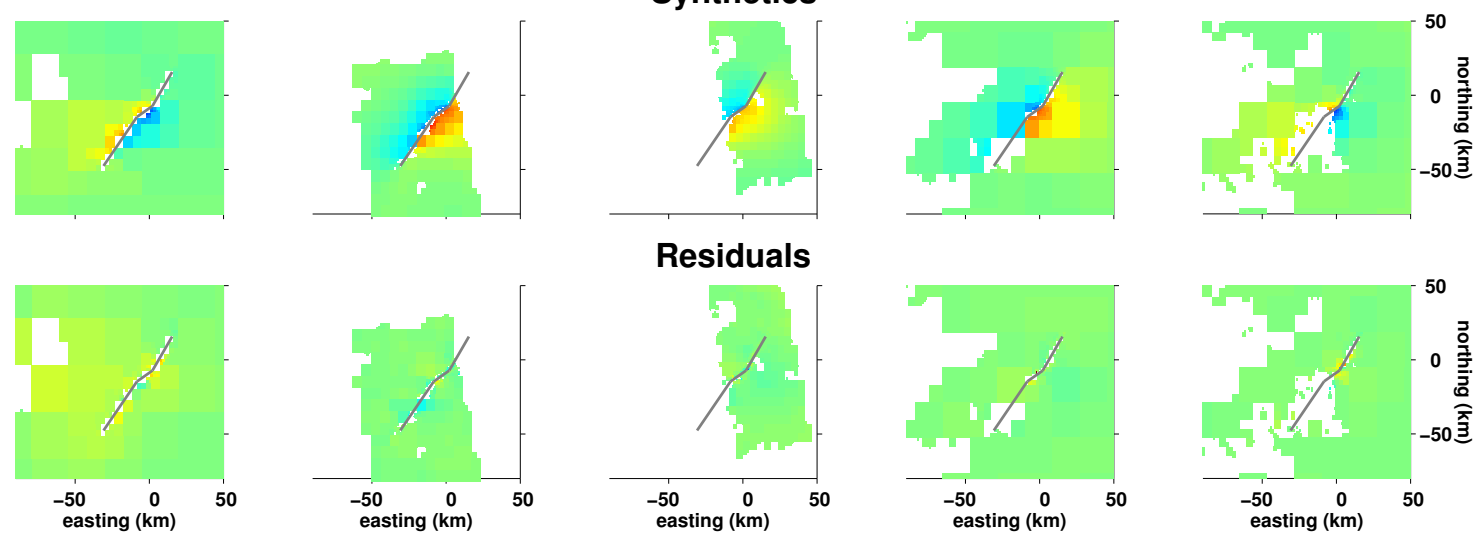

\section{Residuals}
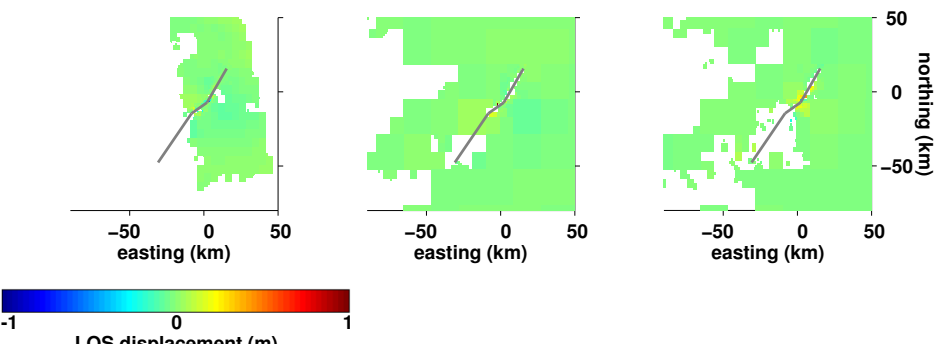

LOS displacement $(m)$

Figure 4: Comparison of observed and modeled LOS displacement fields for 5 interferograms used in this study. Top row: Subsampled interferograms centered on fault. Middle row: Synthetic displacement corresponding to most probable model. Bottom row: Residual displacements. 

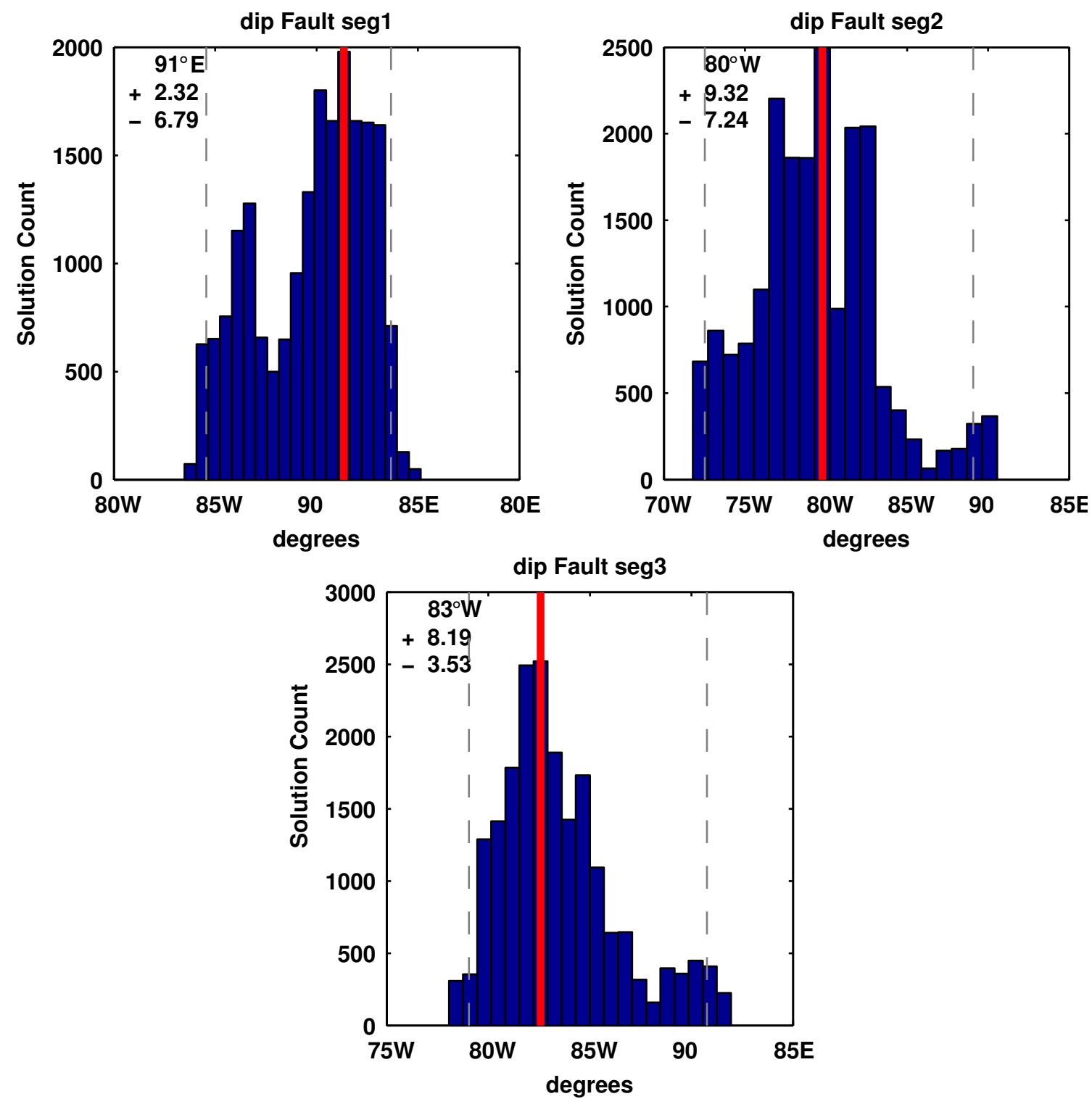

Figure 5: Posterior probability density distributions for dip angle of each fault segment estimated from InSAR data inversion. Solid red lines delineate most probable solutions and dashed lines represent $2 \sigma$ confidence interval. 


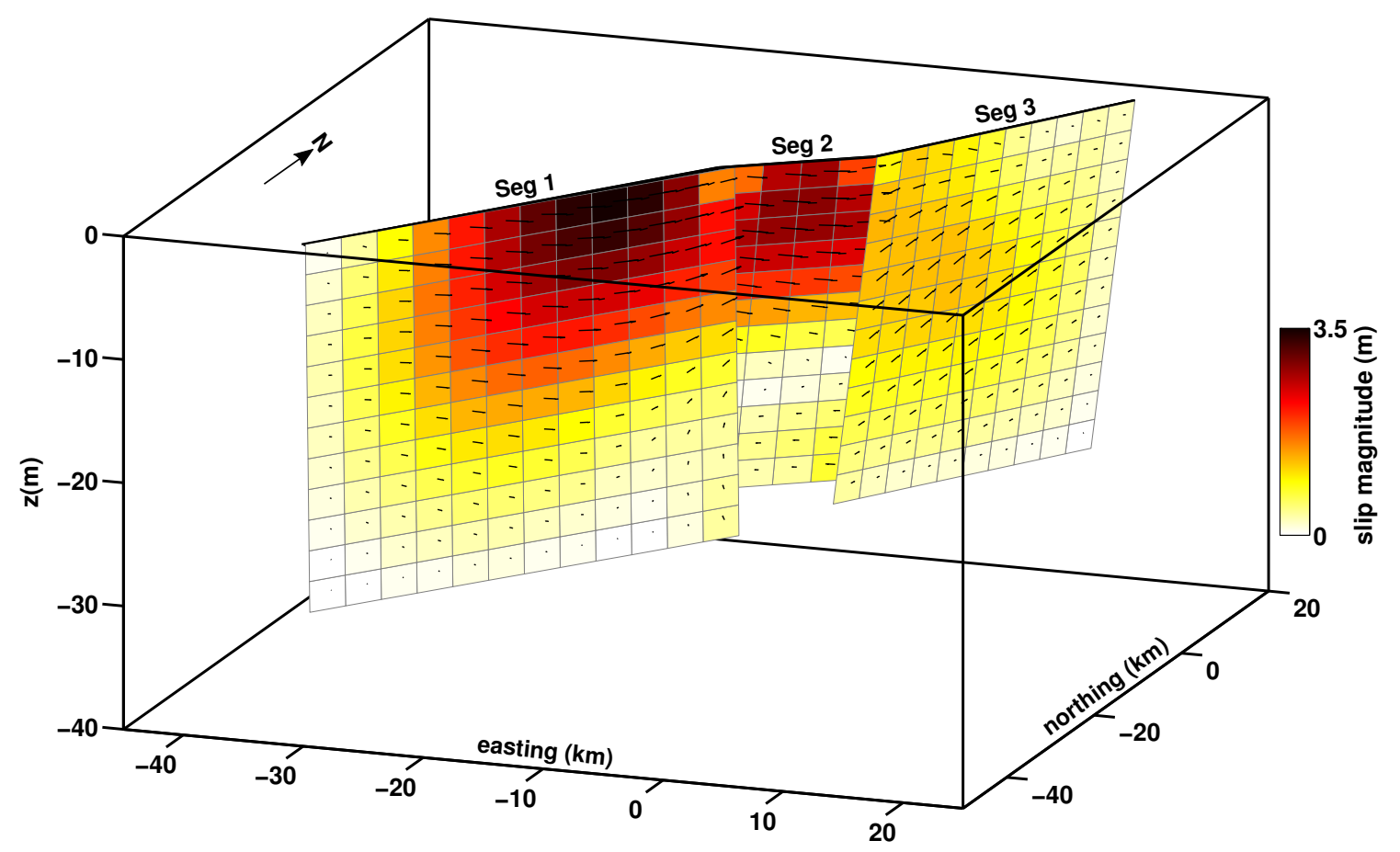

Figure 6: Variable slip solution from InSAR data inversion. Arrows represent direction of motion of fault-wall from the reader's POV. Note that movement is almost purely strikeslip in the region of large moment release, consistent with the NEIC CMT solution (USGS, 2015). 

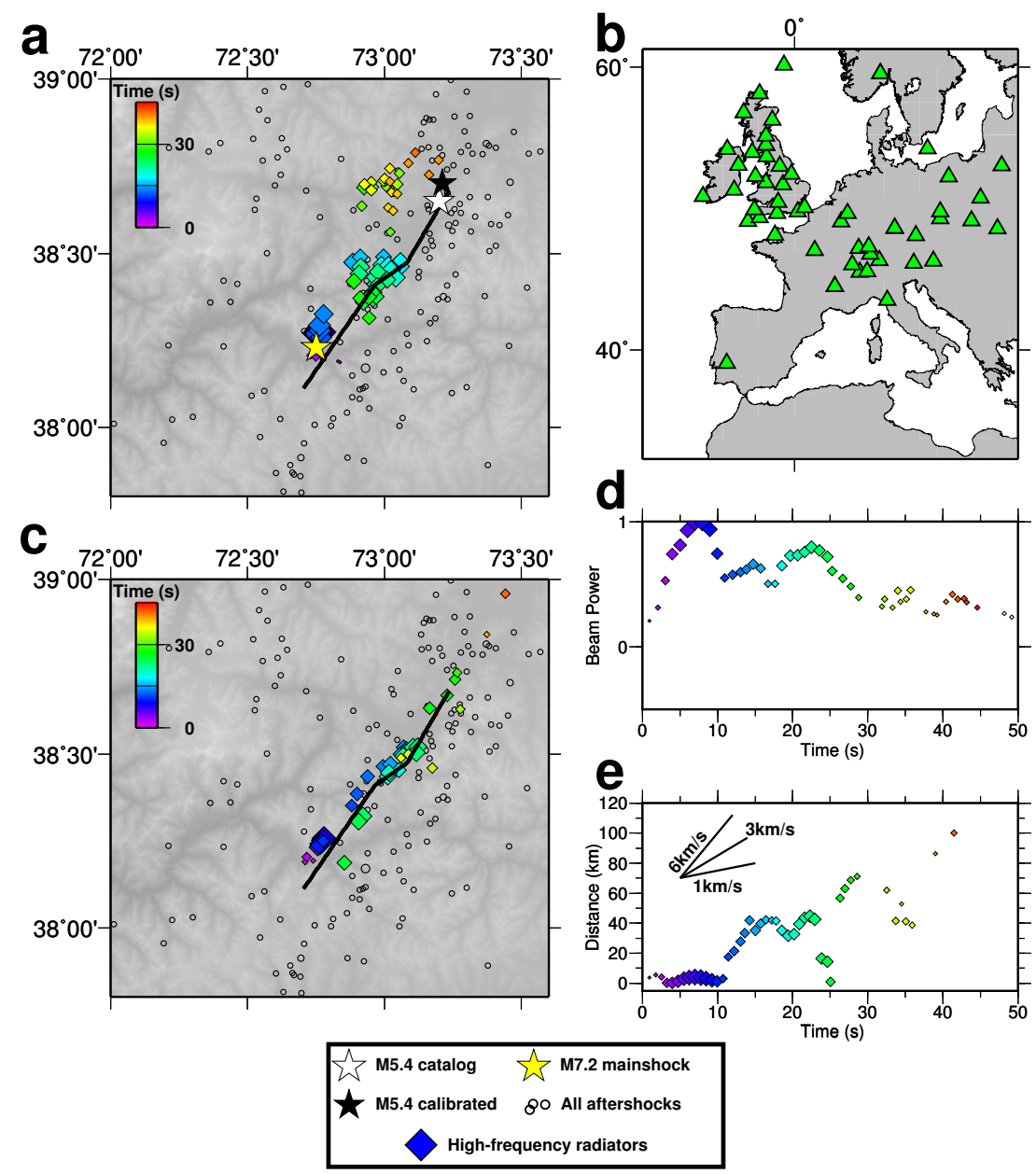

Figure 7: (a) High-frequency radiators locations estimated using back-projection method with data from European seismic network $(b)$. (c) Same as (a) after location calibration. $(d)$ Beam power time function. (e) Time propagation of high-frequency radiators along mean fault direction. In $(a),(c),(d),(e)$, size of diamond symbols scales with relative power and color indicates time since mainshock. 


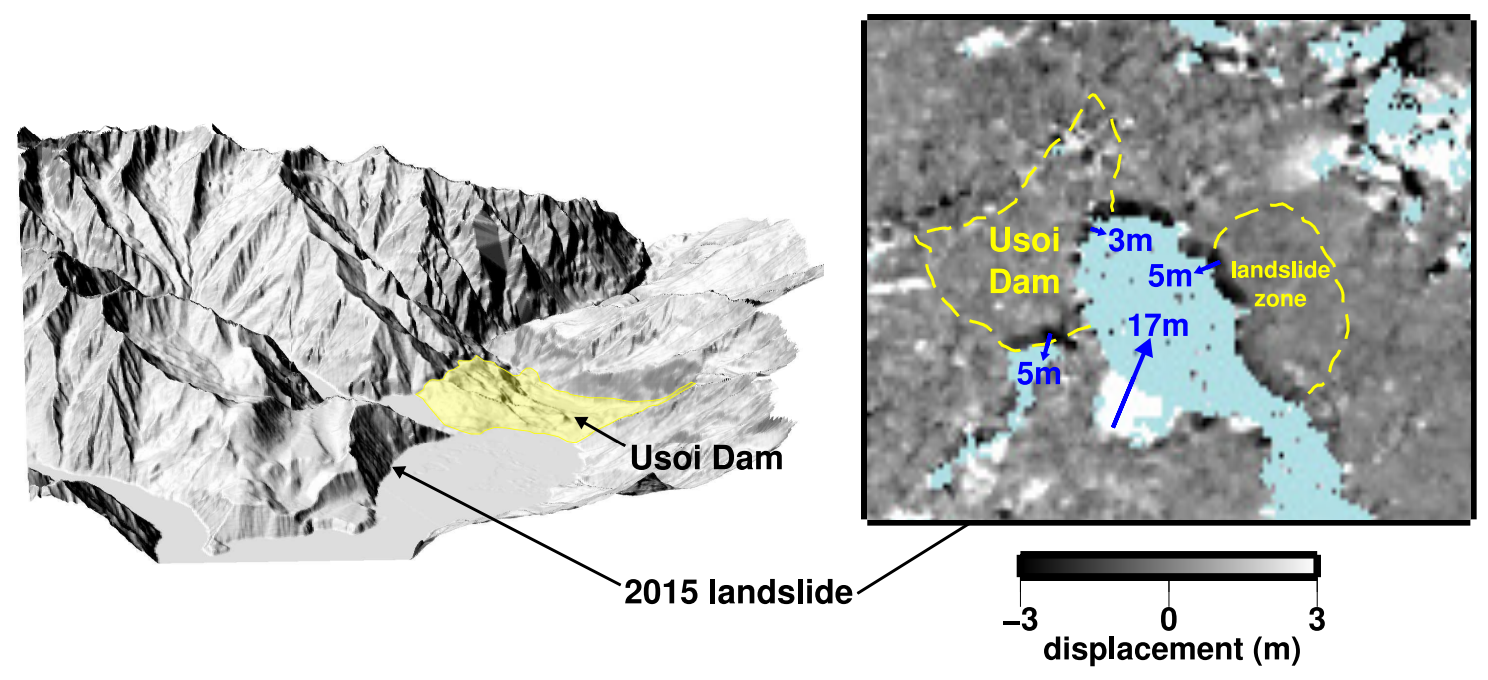

Figure 8: Left: Westward looking view of NW end of Sarez Lake rendered with a shaded, 30 m-posting DEM obtained from Panchromatic Remote-sensing instrument for Stereo Mapping (PRISM, @ JAXA). Terrane that collapsed in 1911 landslide is shown in yellow shade (ISDR, 2000). Flat areas correspond to lake surface: Sarez Lake (foreground), Irkht Bay (left), and Shadau Lake (background). Right: Detail of North component of coseismic displacement field shown in Fig. 2. Gray shade indicating magnitude of displacement is saturated in range between $-3 \mathrm{~m}$ (South) and $3 \mathrm{~m}$ (North) for clarity. Contour lines of Usoi Dam and recognized landslide zone (ISDR, 2000) are indicated. Arrows indicate direction and magnitude of horizontal movement of various sections of lake shore. 
High-frequency seismic radiators

Fault-slip solution

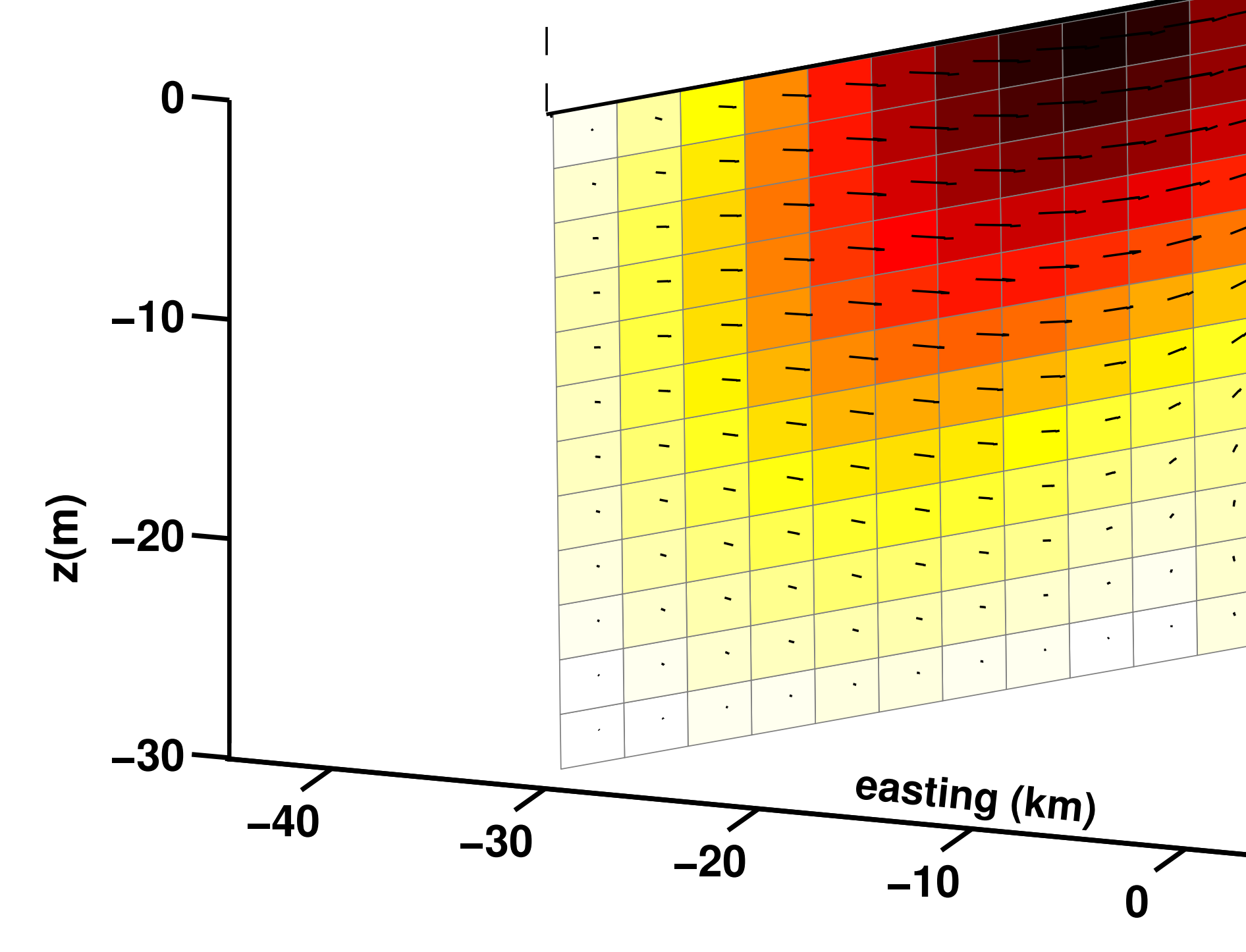

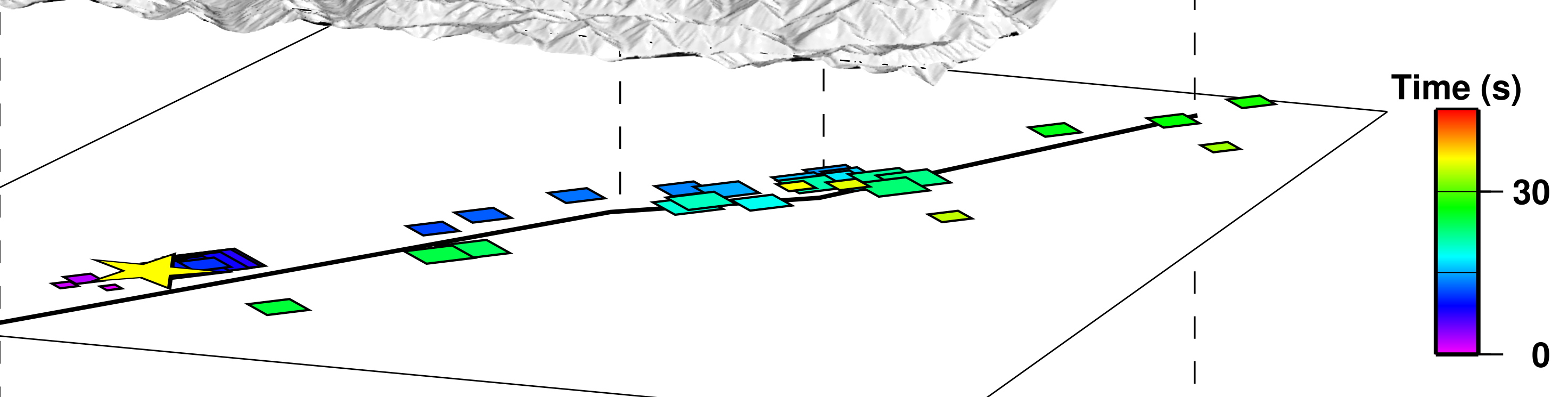

1

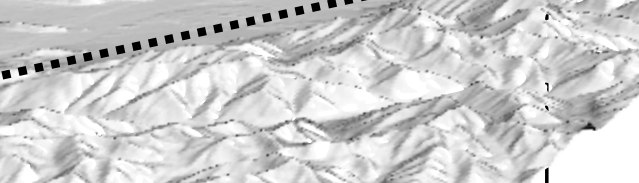

ati 